\title{
Peritoneal NK cells are research Paper Peritoneal NK cells are responsive to IL-15 and percentages are correlated with outcome in advanced ovarian cancer patients
}

\author{
Janneke S. Hoogstad-van Evert ${ }^{1,2}$, Ralph J. Maas ${ }^{2, *}$, Jolien van der Meer ${ }^{2, *}$, Jeannette \\ Cany $^{2}$, Sophieke van der Steen ${ }^{1}$, Joop H. Jansen ${ }^{2}$, Jeffrey S. Miller ${ }^{3}$, Ruud Bekkers ${ }^{1}$, \\ Willemijn Hobo ${ }^{2}$, Leon Massuger ${ }^{1, *}$ and Harry Dolstra ${ }^{2, *}$ \\ ${ }^{1}$ Department of Obstetrics and Gynecology, Radboud University Medical Center, Nijmegen, The Netherlands \\ ${ }^{2}$ Department of Laboratory Medicine, Laboratory of Hematology, Radboud University Medical Center, Nijmegen, The \\ Netherlands \\ ${ }^{3}$ Department of Medicine, Division of Hematology, Oncology, and Transplantation, University of Minnesota, Minneapolis, \\ Minnesota, USA \\ *These authors contributed equally to this work \\ Correspondence to: Janneke S. Hoogstad-van Evert, email: Janneke.Hoogstad-vanEvert@Radboudumc.nl
}

Keywords: natural killer cells; ovarian cancer; IL15; ascites; survival

Received: July 13, $2018 \quad$ Accepted: September 15, $2018 \quad$ Published: October 05, 2018

Copyright: Hoogstad-van Evert et al. This is an open-access article distributed under the terms of the Creative Commons Attribution License 3.0 (CC BY 3.0), which permits unrestricted use, distribution, and reproduction in any medium, provided the original author and source are credited.

\section{ABSTRACT}

The demonstration that ovarian carcinoma (OC) is an immunogenic disease, opens opportunities to explore immunotherapeutic interventions to improve clinical outcome. In this regard, NK cell based immunotherapy could be promising as it has been demonstrated that $\mathrm{OC}$ cells are susceptible to killing by cytokine-stimulated NK cells. Here, we evaluated whether percentage, phenotype, function and IL-15 responsiveness of ascites-derived natural killer (NK) cells is related to progressionfree survival (PFS) and overall survival (OS) of advanced stage OC patients. Generally, a lower percentage of NK cells within the lymphocyte fraction was seen in OC ascites (mean $17.4 \pm 2.7 \%)$ versus benign peritoneal fluids $(48.1 \pm 6.8 \% ; p<0.0001)$. Importantly, a higher CD56+ NK cell percentage in ascites was associated with a better PFS $(p=0.01)$ and OS $(p=0.002)$ in OC patients. Furthermore, the functionality of ascites-derived NK cells in terms of CD107a/IFN-Y activity was comparable to that of healthy donor peripheral blood NK cells, and stimulation with monomeric IL-15 or IL-15 superagonist ALT-803 potently improved their reactivity towards tumor cells. By showing that a higher NK cell percentage is related to better outcome in OC patients and NK cell functionality can be boosted by IL-15 receptor stimulation, a part of NK cell immunity in $O C$ is further deciphered to exploit NK cell based immunotherapy.

\section{INTRODUCTION}

Because ovarian carcinoma $(\mathrm{OC})$ is generally asymptomatic until ascites or metastases beyond the ovaries have developed, patients are often diagnosed in advanced stage. Moreover, the presence and progression of ascites is associated with dismal prognosis and poor quality of life [1]. Current therapy consists of debulking surgery combined with platinum/taxane chemotherapy, but the majority of patients develop a recurrence within 3 years. Especially, for women with advanced stage disease the prognosis is dismal, and despite therapeutic advances the 5 -year survival is only $28 \%$ [2].

Since many studies demonstrated that $\mathrm{OC}$ is an immunogenic disease, further research is needed to explore the opportunities of immunotherapeutic interventions to improve clinical outcome. In this regard, OC ascites is an attractive source to study immune cell function in patients because tumor cells and immune cells are both present. Furthermore, ascites contains a variety of 
immunosuppressive cellular and soluble components that influence the function of tumor-targeting lymphocytes [3-8]. Several studies showed that presence of tumorinfiltrating lymphocytes positively correlated with survival in cancer patients [9-16]. While the importance of CD8+ $\mathrm{T}$ cell infiltration has been clearly demonstrated, the role of infiltrating innate natural killer (NK) cells remains unclear. Interestingly, it was reported that CD103+ tumor-infiltrating $\mathrm{NK}$ cells often co-infiltrate with $\mathrm{CD} 8+\mathrm{CD} 103+\mathrm{T}$ cells, yet the contribution of NK cells to improving outcome is difficult to assess [11]. Therefore, more research is required to decipher the role of $\mathrm{NK}$ cell immunity in OC patients.

NK cells are activated against neoplastic cells through a balance of activating and inhibitory receptors $[17,18]$. Epidemiological research has shown that low NK cell activity is associated with increased cancer risk in humans [19]. For OC patients, decreased functionality of ascites-derived NK cells has been observed [20], which could be partially attributed to the low expression of various activating NK cell receptors including CD16, DNAM-1 and NKp30 [8, 21, 22]. Similarly, ascitesderived $\mathrm{T}$ cells are rather inactive, though proliferation and functionality can be partially restored by cytokine stimulation [23]. NK cells from ascites also exhibit low cytotoxic efficacy, which could be reinvigorated by IL-2 or IL-15 [24]. In this regard, Felices et al. recently reported that the, ALT-803, a fusion protein complex of IL-15 variant (N72D) bound to sushi domain of IL-15R $\alpha$ fused to IgG1 Fc, potently enhanced the function of ascitesderived NK cells and healthy donor peripheral blood NK cells exposed to ascites fluid [25]. Most importantly, many studies demonstrated that OC cells are susceptible to killing by cytokine-stimulated NK cells [26-41].

In this study, we characterized NK cell percentage, phenotype and functionality in ascites of advanced OC patients in relation to clinical outcome, and investigated their responsiveness to IL-15 receptor mediated stimulation. We observed that a higher CD56 + NK cell proportion within the ascites lymphocyte fraction was associated with better progression free survival (PFS; $p=0.01)$ and overall survival (OS; $p=0.002)$ in OC patients. Furthermore, we demonstrated that the cytolytic function of ascites-derived NK cells can be effectively reinvigorated with either monomeric IL-15 or the IL-15 superagonist fusion complex, ALT-803. These findings indicate that boosting NK cell expansion and functionality by immunotherapeutic strategies could improve survival in OC patients.

\section{RESULTS}

\section{Patient cohort characteristics}

For this study, we selected ascites fluid samples collected at diagnosis or first surgery of patients with stage
IIIc or IV high-grade serous papillary OC. The mean age of the selected OC patient cohort $(n=20)$ was $64 \pm 8.8$ years and $48 \pm 8.1$ years for the benign gynecological disorder control group $(n=10)$. The median OS and PFS of the OC patient cohort at time of analysis was 19 months and 6 months, respectively. Based on the median OS, the patient cohort was divided in two groups: i.e. poor survival group $(n=10)$ with an OS of less than 19 months and good survival group $(n=10)$ with an OS of more than 19 months (Table 1). The OS and PFS in the good survival group were $32.9 \pm 11.2$ and $19.7 \pm 16.4$ months, respectively. Whereas the OS and PFS in the poor survival group was only $10.3 \pm 4.4$ and $3.2 \pm 2.3$ months, respectively. Further characteristics of the two OC patient groups are shown in Table 1. Patients in the good survival group were younger and were less often postmenopausal. In both groups, half of the OC patients were treated with primary surgery, and half with neo-adjuvant chemotherapy. CA-125 levels were higher in the good survival group.

\section{High peritoneal NK cell proportion within the lymphocyte fraction is associated with better survival of OC patients}

First, we assessed the percentages of NK, NKT and $\mathrm{T}$ cells within the lymphocyte fraction in cryopreserved ascites samples of the selected OC patients by flow cytometry and compared those with peritoneal fluid of 10 patients with a benign gynecological disorder. Within the total cell fraction OC ascites contained $38.8 \pm 24.8 \%$ lymphocytes, $40.5 \pm 24.7 \%$ CD $45+$ non-lymphocytes and $16.4 \pm 23.5 \%$ CD45- non-hematopoietic tumor cells, and the benign samples contained $58.7 \pm 40.4 \%$ lymphocytes and $36.5 \pm 34.1 \%$ non-lymphocytes within CD45+ leucocytes (Figure 1A). Within the lymphocytes a significantly lower CD3-CD56+ NK cell percentage was seen in OC patient ascites (mean $17.1 \pm 2.7 \%$ ) compared to benign peritoneal fluid $(48.1 \pm 6.8 \%$, $p<0.0001$; Figure 1B). Furthermore, lower CD3+ T cell and $\mathrm{CD} 3+\mathrm{CD} 56+\mathrm{NKT}$ cell percentages were observed within the lymphocyte population in OC patient ascites. The population of non T-, non-NKT, non-NK cells in the lymphocyte gate, presumably B cells, was more prominent in the malignant samples (Figure 1B). Notably, the group of OC patients with poor survival had $14.5 \pm 3.6 \%$ NK cells versus $23.6 \pm 4.0 \%$ in the patients with good survival (Figure 1C). In addition, we observed a significant shift in the $\mathrm{CD} 56^{\mathrm{dim} / \text { right }}$ ratio in $\mathrm{OC}$ patients in comparison to peritoneal fluid of patients with a benign gynecological disorder (Figure 1D). Generally, in healthy donor blood around $90 \%$ cytotoxic CD56 ${ }^{\mathrm{dim}}$ and $10 \%$ regulatory CD56 ${ }^{\text {bright }}$ cells are present [42]. In contrast, in the benign ascites samples we found $32.4 \pm 3.7 \% \mathrm{NK}^{\mathrm{dim}}$ cells and 67.5 $\pm 3.7 \%$ CD56 $6^{\text {bright }}$ cells, respectively. In OC patient ascites, however, the ratio was more in favor of the cytotoxic $\mathrm{CD}^{\text {dim }}{ }^{\mathrm{dim}}$ population with $54.7 \pm 4.0 \% \mathrm{CD}^{\mathrm{dim}}$ and 
Table 1: Patient characteristics

\begin{tabular}{lccc}
\hline & Characteristics & Good survival $(\boldsymbol{n}=\mathbf{1 0})$ & Poor survival $(\boldsymbol{n}=\mathbf{1 0})$ \\
\hline Baseline & Age mean (SD) & $57.2(8.4)$ & $69.0(11.4)$ \\
& CA-125 mean (95\% CI) & $1532(641-2423)$ & $1268(199-2337)$ \\
\multirow{3}{*}{ Treatment } & Postmenopausal & $70 \%$ & $90 \%$ \\
\multirow{3}{*}{ Debulking } & Neoadjuvant Chemotherapy & $50 \%$ & $60 \%$ \\
& Primary surgery & $50 \%$ & $40 \%$ \\
& Complete Debulking & $20 \%$ & $20 \%$ \\
\multirow{3}{*}{ Survival } & (Sub-) Optimal Debulking & $80 \%$ & $70 \%$ \\
& No Debulking & $0 \%$ & $10 \%$ \\
& PFS mean (SD) & $19.7(16.4)$ & $3.2(2.3)$ \\
& OS mean (SD) & $32.9(11.2)$ & $10.3(4.4)$ \\
\hline
\end{tabular}

$45.4 \pm 4.0 \% \mathrm{CD}^{\text {bright }}$ cells, compared to the benign peritoneal fluids (Figure 1D).

Next, we divided the OC patients in two groups based on the median ascites NK cell percentage within the lymphocyte fraction into high (mean $31.4 \pm 9.4 \%$ ) and low (mean $8.9 \pm 4.6 \%$ ) percentage groups. We observed that both OS $(p=0.002$, hazard ratio $=5.7)$ and PFS $(p=0.01$, hazard ratio $=4.7)$ were significantly better in OC patients with a high peritoneal NK cell percentage versus patients with a low NK cell percentage in the lymphocyte fraction (Figure 1E and 1G). Notably, this relationship was not observed for $\mathrm{CD} 3+\mathrm{T}$ cell percentages in ascites (Figure 1F and $1 \mathrm{H}$ ). Interestingly, in the high NK group three patients are still alive after a follow-up of $\geq 50$ months. Altogether, these data indicate that the CD56+ NK cell percentage within the lymphocyte fraction in ascites fluid of OC patients is positively correlated with clinical outcome.

\section{Ascites-derived NK cells of poor survival ovarian carcinoma patients exhibit low expression levels of activating receptors}

Next to the percentage of NK cells in ascites, we studied whether survival of OC patients was associated with differential expression of NK cell activating receptors. Hereto, we performed flow cytometry analysis on the ascites-derived NK cells of the selected patient cohort and benign ascites controls (Figure 2). While 2B4 had equally high positivity on both benign and malignant peritoneal fluid NK cells, NKG2D was low to undetectable on these NK cells. Remarkably, NKp30 was almost absent on NK cells in malignant samples (mean $3 \%$ ), whereas it was significantly higher on NK cells from benign samples (mean 79\%). NKG2A can suppress activation, and shows no significant differences between benign and malignant samples. Moreover, NKp46 and DNAM-1 were significantly lower expressed on NK cells in malignant samples, especially in patients with a poor OS. Together, these data indicate that ascites NK cells of OC patients with poor survival have significantly lower expression of activation receptors on their surface.

\section{Ascites-derived NK cells possess equal cytotoxic function as peripheral blood NK cells from healthy donors}

Next, we addressed the functional activity of peritoneal fluid NK cells of OC patients in comparison to peripheral blood (PB)-NK cells from healthy donors. Here, we cultured MNCs from ascites of OC patients or PB of healthy controls overnight in the presence of IL-15, whereupon total cells were challenged for 4 hours with either K562 (control), SKOV-3 OC or without tumor cells and subsequently analyzed by flow cytometry. We examined expression of the activation markers CD69 and TRAIL, the degranulation of NK cells using CD107a, and intracellular IFN- $\gamma$ positivity. Both ascites and control NK cells showed high CD69 expression, while TRAIL levels decreased upon tumor challenge (Figure 3A and 3B). Furthermore, ascites-derived NK cells were capable of exerting a CD107a degranulation and IFN- $\gamma$ response against K562 cells (Figure 3C and 3D). However, reactivity of ascites-derived NK cells greatly varied between different $\mathrm{OC}$ patients, therefore no significant differences were observed as compared to healthy donor NK cells. Notably, for both OC ascites and healthy donor NK cells the response against SKOV-3 OC cells was poor. Together, these data demonstrate that OC ascitesderived NK cells have equivalent degranulation and IFN- $\gamma$ secretion capacity as healthy donor PB-NK cells, yet responsiveness against SKOV-3 OC cells is limited.

\section{Functionality of ascites NK cells can be effectively boosted by IL-15 or ALT-803 stimulation}

To improve peritoneal NK cell reactivity against OC, we investigated whether boosting with monomeric recombinant human IL-15 or the human IL-15 superagonist 

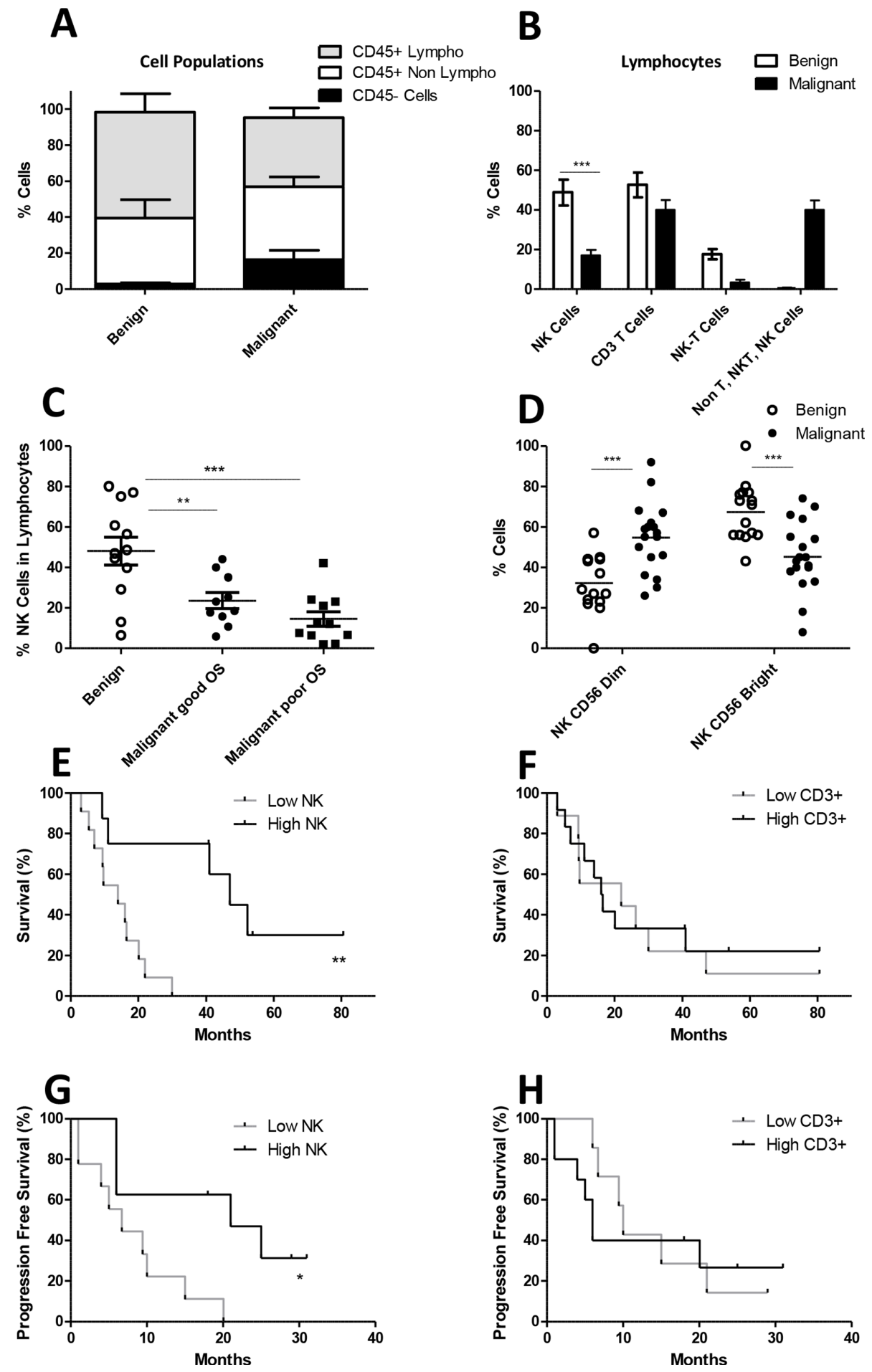

Figure 1: NK, NKT and T cell percentage in benign ascites and ascites from ovarian cancer patients. (A) Fraction of CD45+ lymphocytes (white), CD45+ non-lymphocytes (grey) and CD45- cells (black) cell populations within peritoneal fluid of benign compared to malignant ovarian cancer patients, based on flow cytometric analysis of CD45 expression and forward/side scatter. (B) Percentage of NK cells, T cells, NKT cells and other lymphocytes within benign and malignant ascites. The percentage NK cells within the lymphocyte population is significantly different, two tailed $T$-test $p<0.0001$. (C) Within the lymphocyte population the percentage of NK cells is depicted. The group of malignant ovarian carcinoma ascites patients is divided into good and poor survival based on the median survival of the analyzed patient cohort $(n=20)$. (D) The NK cell population is subdivided based on CD56 bright and CD56 dim cells. (E) Overall survival curve of OC patients groups with low and high CD56+ NK cell percentages in ascites. (F) Overall survival curve of OC patients groups with low and high $\mathrm{CD} 3+\mathrm{T}$ cell percentages in ascites. $(\mathbf{G}-\mathbf{H})$ Progression free survival curves for low and high $\mathrm{CD} 56+$ $\mathrm{NK}$ cell and $\mathrm{CD} 3+\mathrm{T}$ cell percentages in ascites. Error bars represent mean $+\mathrm{SEM}$. When 2 groups were compared the Student $T$-test was used whereas a one-way ANOVA with Bonferroni correction was performed when comparing 3 groups. ${ }^{* * *} p=0.001$. 
fusion complex, ALT-803. Interestingly, IL-15 receptormediated stimulation already enhanced CD107a expression and IFN- $\gamma$ secretion capacity of the NK cells in the absence of tumor challenge (Figure 4A and 4D). Most importantly, ascites-derived NK responsiveness against K562 and especially SKOV-3 OC cells could be potently augmented by IL-15 or ALT-803 stimulation ( $p<0.001$ for CD107a and $p<0.01$ for IFN- $\gamma$; Figure 4B, 4C, 4E and 4F). These data demonstrate that the function activation of NK cells in ascites can be efficiently rescued with IL-15 or ALT-803.

\section{DISCUSSION}

NK cells are activated against cancer cells via activating and inhibitory receptors, and the balance in these signals determines the magnitude of their activity. $[17,18]$ Epidemiological research has shown that low NK cell activity is associated with increased cancer risk in humans [19]. Moreover, NK cells have been identified to play a role in tumor surveillance due to enhanced surface expression of ligands for activating receptors on tumor cells by the DNA damage response [43]. Together these studies underscore the contribution of NK cell function in anti-cancer immunity. However, there is limited data on the contribution of NK cell immunity on the clinical outcome of women with ovarian carcinoma. In the present study, we found that the percentage of CD56+ NK cells within the lymphocyte fraction in ascites fluid is related to OS and PFS, and that ascites-derived NK cells have lower expression of activation markers than benign peritoneal fluid NK cells. Although, ascites-resident NK cells have poor reactivity against SKOV-3 OC cells (similarly as PB-NK cells) they can be effectively boosted by IL-15 receptor mediated stimulation.
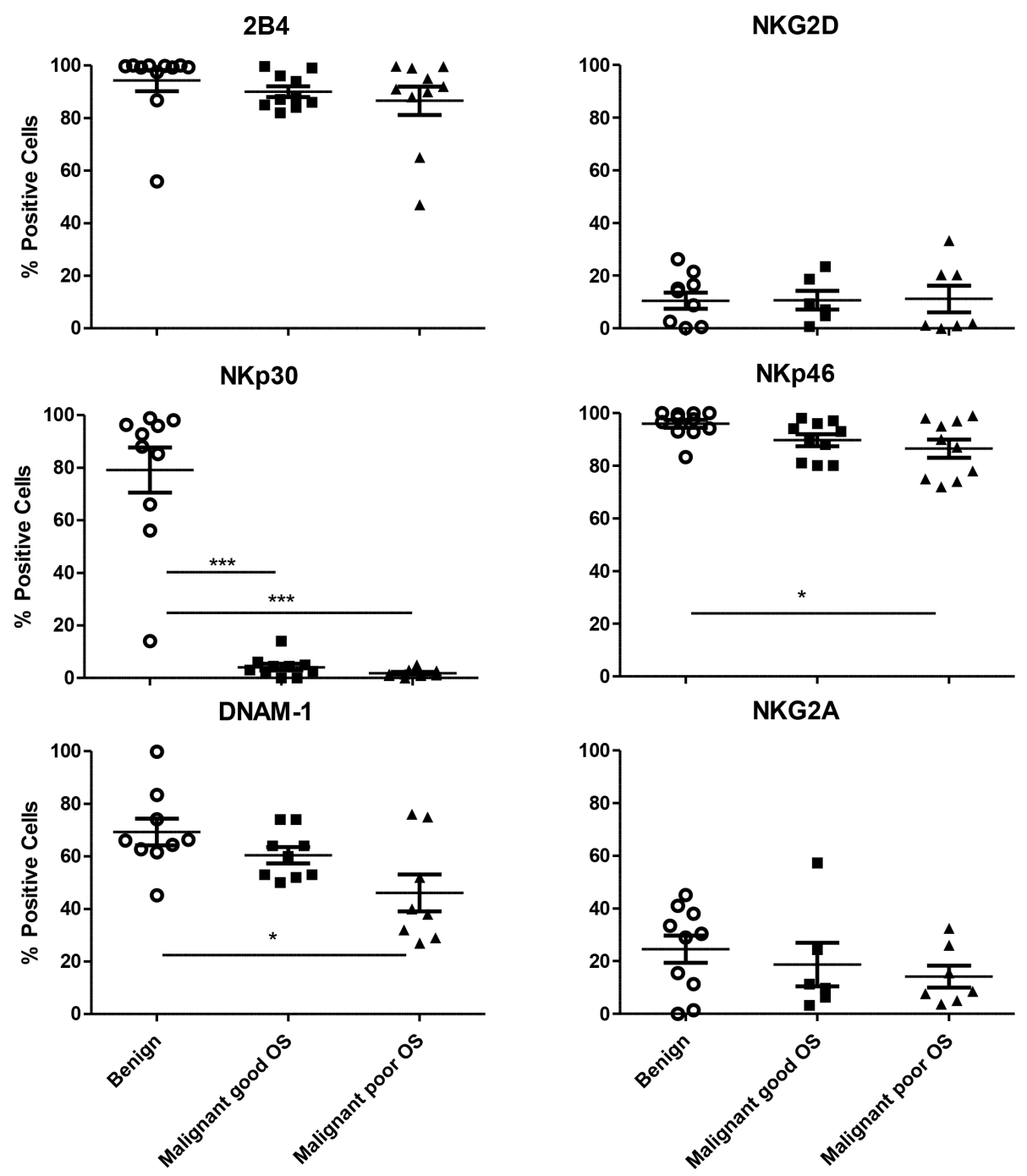

Figure 2: Expression of activating receptors on CD45+CD3-CD56+ NK cells. Percentage positive 2B4, NKG2D, NKp46, NKp30, DNAM-1 and NKG2A NK cells of CD56+ NK cells in benign and malignant peritoneal fluid. The group of malignant ovarian carcinoma ascites patients is divided into lower than median overall survival and higher than median overall survival. Error bars represent mean + SEM. One way ANOVA with Bonferroni correction was performed when comparing the groups. ${ }^{*}=p<0.05,{ }^{* * *}=p<0.001$. 
In our current study, OC patients were randomly selected from our ascites biobank. Nevertheless, as large amounts of ascites MNCs was required for these studies, we thereby selected automatically a group of patients with a relatively poor prognosis. A remarkably high percentage of these patients did not undergo complete debulking surgery, however since rates of complete debulking were comparable in both the poor and good OS groups, we believe that the impact of incomplete debulking on our NK cell correlative results is limited. Notably, the OS of our patient cohort is comparable to a large national cohort [44]. Although there were age differences between the benign control and the $\mathrm{OC}$ groups we do not expect impact on our findings, as it has been reported for PB that NK cell percentages are very stable and do not change with age [45].

Notably, a higher NK cell percentage within the lymphocyte fraction was found in peritoneal fluid of benign control subjects than in ascites of OC patients. Often peritoneal fluid of healthy individuals is used in endometriosis research, and also in this disease a significantly lower percentage of NK cells in peritoneal fluid has been reported [46]. In OC the only relation between clinical outcome and NK cells in ascites was described by Dong et al., and they reported CD16 positive cells to be associated with poorer outcome of OC patients. Unfortunately, CD56 expression was not evaluated in their report [12]. Our paper is the first report to show a relationship between the CD56+ NK cell proportion within the ascites lymphocyte fraction and clinical outcome parameters. While the importance of CD8+ $\mathrm{T}$ cell infiltration within $\mathrm{OC}$ tumors has been clearly demonstrated, and also $\mathrm{CD} 3+\mathrm{T}$ cells in ascites have been found to correlate with better outcome [47, 48], a relation between $\mathrm{CD} 3+\mathrm{T}$ cell percentage and survival was not observed in our cohort. Besides percentages, absolute numbers of infiltrating lymphocytes is an important parameter for correlation with clinical outcome. However, as volume and cellular density in ascites differed greatly between OC patients, we believe that the percentage within the lymphocyte population was the most objective way to compare cell populations. For future research, it would be interesting to investigate how ascites NK cells differ from blood NK cell numbers, phenotype and function in the same OC patient.

It has been previously reported that OC ascites NK cells have been described to exhibit lower expression of the activating markers NKp30, NKp46, NKG2D and DNAM-1 compared to healthy donor PB-NK cells $[8$, 49]. In our study, we observed the same significantly lower expression of NKp30, NKp46 and DNAM-1 on OC ascites-derived NK cells compared to NK cells from benign peritoneal fluid. However, the relationship between NKG2D and prognosis was not found in our dataset. Interestingly, we observed a significant lower NK cell expression of NKp30 in poor prognosis versus good prognosis ascites samples, suggesting that NKp30 expression changes in the poor prognosis OC environment. The same has been reported in acute myeloid leukemia, where NKp30 is proposed as a prognostic biomarker based on its low expression on NK cells in poor prognosis patients [50]. Further validation in a larger patient cohort is required to establish prognostic biomarkers in $\mathrm{OC}$ patients.

In our functional studies, ascites-derived NK cells demonstrated equal degranulation and cytokine secretion potential as healthy donor PB-NK cells. This corresponds with findings by Felices et al. who showed comparable levels of CD107a after stimulation in the presence or absence of tumor cells [25]. In contrast, other reports demonstrated that

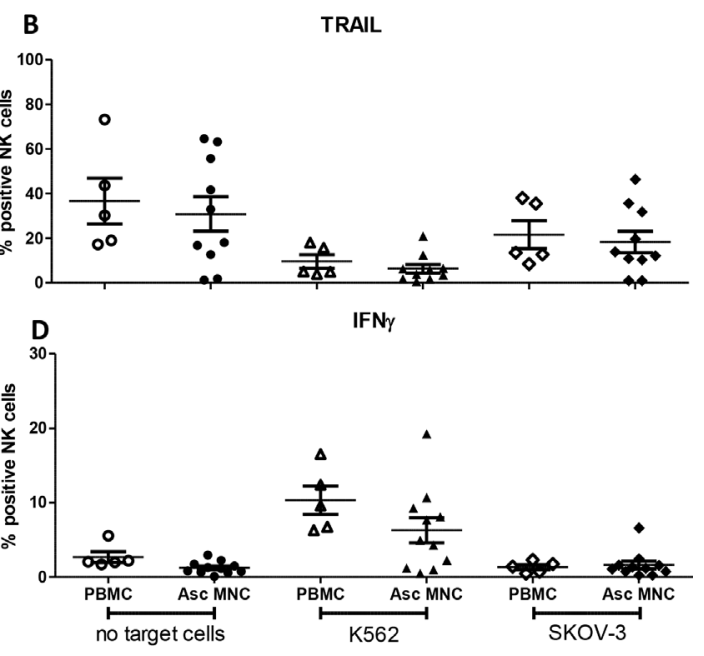

Figure 3: Degranulation assay comparing NK cells in healthy donor (HD) peripheral blood mononuclear cells (PBMCs) with ascites mononuclear cells (MNCs). Percentage CD56+ NK cells positive for (A) CD69, (B) TRAIL, (C) CD107a, (D) IFN- $\gamma$, after $4 \mathrm{~h}$ stimulation with no target cells, K562 or SKOV-3 tumor cells. Error bars represent mean + SEM. Open symbols depict HD PBMCs, closed symbols depict ascites MNCs. One way ANOVA with Bonferroni correction was performed when comparing the groups. 
ascites-derived NK cells were dysfunctional, with decreased CD16 expression and low cytotoxic capacity $[6,51,52]$. Here, we showed that ascites-derived NK cells were highly capable of recognizing K562 tumor cells, but exhibited poor SKOV-3 OC cell reactivity. Most importantly, we demonstrated that stimulation with IL-15 or ALT-803 could reinvigorate $\mathrm{NK}$ cell degranulation and IFN- $\gamma$ production, especially against SKOV-3 OC cells. Although our ex vivo studies did not show any difference between IL-15 and ALT803 , ALT-803 is likely more potent in long-term assays and in vivo because of its longer half-life [53, 54].

Concluding, this report shows a significant association between the percentage and phenotype of NK cells within the lymphocyte fraction in peritoneal fluid and survival of OC patients. Moreover, we demonstrated that peritoneal NK cell reactivity against OC tumor cells can be efficiently boosted by IL-15 receptor-mediated stimulation. The relationship between availability of NK cells in the abdominal cavity and the potentiating effect of IL-15 indicates that intraperitoneal NK cell adoptive transfer combined with IL-15 administration could be an interesting new therapy for OC patients to improve outcome. Currently, a phase 1 clinical trial testing intraperitoneal ALT-803 therapy in OC patients is enrolling patients in the US (NCT0354909) and a phase 1 clinical trial on intraperitoneal NK cell therapy exploiting CD34+ progenitor-derived NK cells is open in the Netherlands (NCT03539406). By demonstrating that high NK cell percentages are associated with better outcome in
OC patients and peritoneal NK cell functionality can be boosted by IL-15 receptor stimulation, a part of NK cell immunity in OC is further deciphered to exploit NK cell based immunotherapy in these poor prognosis patients.

\section{MATERIALS AND METHODS}

Ascites fluid samples were prospectively collected at diagnosis or first surgery of patients with stage IIIc or IV high-grade serous papillary OC between January 2009 and January 2013 at the Radboud University Medical Center (RUMC). Study approval was given by the Regional Committee for Medical Research Ethics (CMO 2013-516) and performed according to the Code for Proper Secondary Use of Human Tissue (Dutch Federation of Biomedical Scientific Societies, www. federa.org). Ascites was filtered using a $100 \mu \mathrm{m}$ filter, washed and MNCs were isolated by Ficoll-Hypaque density gradient centrifugation. Subsequently, obtained cells were cryopreserved and stored in liquid nitrogen until use. From this biobank we randomly selected ascitic cell samples from $20^{\circ} \mathrm{C}$ patients. For the benign control group, samples were collected at benign gynecological surgeries. Main indication for diagnostic laparoscopy was abdominal pain, samples were included only if pathological findings were absent. Detection of cysts, endometriosis and adhesions at laparoscopy were exclusion criteria. These benign samples were processed and analyzed on the day of surgery. Medical records were retrospectively reviewed
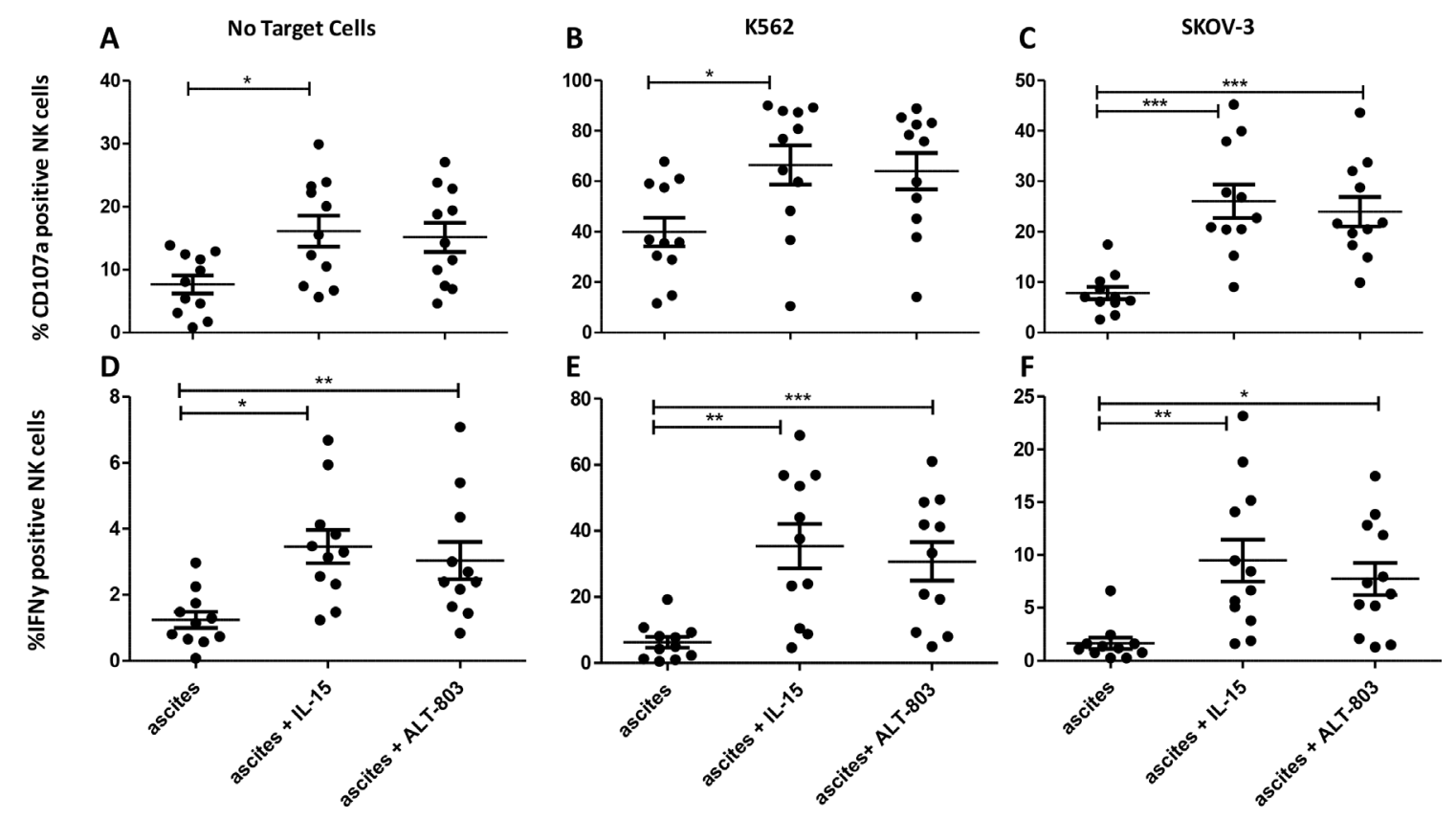

Figure 4: Degranulation assay comparing ascites CD56+ NK cells with and without monomeric IL-15 or ALT-803 stimulation. (A-C) Percentage CD56+ NK cells positive for CD107a after $4 \mathrm{~h}$ co-culture with no stimulation (A), K562 cells (B) or SKOV-3 cells (C). (D-F) Percentage CD56+ NK cells positive for IFN- $\gamma$ after $4 \mathrm{~h}$ co-culture with no stimulation (D), K562 cells (E) or SKOV-3 cells (F). Error bars represent mean + SEM. One way ANOVA with Bonferroni correction was performed when comparing the groups. ${ }^{*}=p<0.05,{ }^{* *}=p<0.01,{ }^{* * *}=p<0.001$. 
and relevant clinical and pathology data were extracted. Time of diagnosis was considered to be the date of the primary surgical procedure. Time from diagnosis to death was calculated for OS. PFS was calculated as time of last chemotherapy till diagnosis of biochemical or radiologic recurrence. Median survival was expressed in months.

Patients were divided in groups for Figure $1 \mathrm{C}$ and Figure 2 based on median overall survival, poor survival are the patients with an overall survival of less than the median (19 months), good survival are the patients with an overall survival of more than 19 months.

For Figure $1 \mathrm{E}$ and $1 \mathrm{G}$ patients were divided based on median NK cell frequency, for Figure $1 \mathrm{~F}$ and $1 \mathrm{H}$ groups are divided by median CD3 cell frequency.

\section{Flow cytometry}

MNCs were stained with labeled antibodies, CD3 ECD (Biolegend), CD45 Krome Orange (R\&D systems), CD56 PE-Cy5 (Biolegend), CD16 APC-Cy7 (Biologend), CD326 PerCPCy5.5 (Biolegend). Phenotypic analysis was performed using DNAM-1 FITC (Becton Dickinson), 2B4 FITC (Biolegend), NKG2A APC (Beckman Coulter), NKG2D APC (Biolegend), NKp30 PE (Biolegend) and NKp46 PE(Biolegend), isotype controls for IgG1 and IgG2a, (all Biolegend). Dead cells were stained with 1:1000 diluted sytox blue (Life Technologies; Invitrogen). Flow cytometry analysis was performed on a Gallios flow cytometer from Beckman Coulter. Analysis was done in Kaluza 1.5 (Beckman Coulter). Gating strategy is shown in Supplementary Figure 1.

\section{K562 and SKOV-3 cell lines}

OC cell line SKOV-3 was cultured in Roswell Park Memorial Institute medium (RPMI 1640; Gibco) medium supplemented with 10\% Fetal Calf Serum (FCS; Integro). The chronic myeloid leukemia cell line K562 was cultured in Iscove's Modified Dulbecco's Medium (IMDM) with $10 \% \mathrm{FCS}$.

\section{Functional assay (CD107a and IFN- $\gamma$ )}

After thawing ascites MNCs or PBMCs were cultured overnight with $1 \mathrm{nM}$ IL-15 (Immunotools), $1 \mathrm{nM}$ ALT-803 (Altor Bioscience) or without cytokine support in IMDM with $10 \% \mathrm{FCS}$ and 1\% penicillin/streptomycin $(\mathrm{p} / \mathrm{s})$. Subsequently, $1 \times 10^{6}$ cells were co-cultured with $0.5 \times 10^{6} \mathrm{~K} 562$ cells, $0.5 \times 10^{6} \mathrm{SKOV}-3$ cells or without target cells for 4 hours in IMDM with $10 \%$ FCS and 1\% p/s and anti-CD107a PE-Cy7 (Biolegend) in a 24-well plate. After $1 \mathrm{~h}$ of co-culture, brefeldin A (BD) was added. Finally, cells in each well were gently resuspended and stained with labeled antibodies, CD56 BV510 (Biolegend), CD45 AF700 (Invitrogen), CD3 ECD (Beckman Coulter), CD69 BV421 (Biolegend) or isotype IgG1BV421 (BD biosciences), and TRAIL APC or isotype IgG1 APC (both Biolegend). Dead cells were stained with 1:1000 in PBS diluted eFluor780. Next, cells were fixed, permeabilized and stained with anti-IFN- $\gamma$ or isotype IgG1 FITC (BD biosciences) and anti-perforin or isotype $\operatorname{IgG} 2 \mathrm{~b}$ PE (Biolegend). Flow cytometry acquisition was performed on a Gallios flow cytometer from Beckman Coulter. Analysis was done in Kaluza 1.5 (Beckman Coulter).

\section{Statistical analysis}

Statistical analysis was performed in Graphpad Prism software package version 5.03. Flow cytometry data was expressed as percentage positive cells. Data were analyzed using two-way ANOVA for group comparison or one-way ANOVA with Bonferroni post-hoc correction if more than two groups were compared. Unpaired $T$-tests were performed for comparison of two single groups, as indicated. Differences were considered significant when the $p$ value was $<0.05$. Survival curves were analyzed by Log rank (Mantel-Cox) test.

\section{Author contributions}

JHE designed research, performed experiments, analyzed data, and wrote the manuscript; RM and JvdM performed experiments, analyzed data and revised the manuscript; JC and WH designed research and revised the manuscript; SS co-collected ascites samples, JJ, JM, $\mathrm{RB}$ and LM provided advice and reviewed manuscript; HD designed and supervised research and revised the manuscript.

\section{ACKNOWLEDGMENTS}

The authors thank Sarah Alter, Peter Rhode and Hing Wong from Altor Bioscience for kindly providing the ALT-803 used in this study. Moreover we thank Sarah Alter for reviewing the manuscript.

\section{CONFLICTS OF INTEREST}

The authors have no financial conflicts of interest.

\section{FUNDING}

Research was supported by a grant from the Dutch Cancer Society KWF, grant number 2015-7507 and Ruby and Rose foundation grant number 2016-01.

\section{REFERENCES}

1. Ahmed N, Stenvers KL. Getting to know ovarian cancer ascites: opportunities for targeted therapy-based translational research. Front Oncol. 2013; 3:256. 
2. Siegel RL, Miller KD, Jemal A. Cancer Statistics, 2017. CA Cancer J Clin. 2017; 67:7-30.

3. Fumita Y, Tanaka F, Saji F, Nakamuro K. Immunosuppressive factors in ascites fluids from ovarian cancer patients. Am J Reprod Immunol. 1984; 6:175-178.

4. Giuntoli RL 2nd, Webb TJ, Zoso A, Rogers O, Diaz-Montes TP, Bristow RE, Oelke M. Ovarian cancer-associated ascites demonstrates altered immune environment: implications for antitumor immunity. Anticancer Res. 2009; 29:2875-2884.

5. Onsrud M, Bosnes V, Grahm I. cis-Platinum as adjunctive to surgery in early stage ovarian carcinoma: effects on lymphoid cell subpopulations. Gynecol Oncol. 1986; 23:323-328.

6. Lukesova S, Vroblova V, Tosner J, Kopecky J, Sedlakova I, Cermakova E, Vokurkova D, Kopecky O. Comparative study of various subpopulations of cytotoxic cells in blood and ascites from patients with ovarian carcinoma. Contemp Oncol (Pozn). 2015; 19:290-299.

7. Santin AD, Hermonat PL, Ravaggi A, Bellone S, Roman JJ, Smith CV, Pecorelli S, Radominska-Pandya A, Cannon MJ, Parham GP. Phenotypic and functional analysis of tumorinfiltrating lymphocytes compared with tumor-associated lymphocytes from ascitic fluid and peripheral blood lymphocytes in patients with advanced ovarian cancer. Gynecol Obstet Invest. 2001; 51:254-261.

8. Belisle JA, Gubbels JA, Raphael CA, Migneault M, Rancourt C, Connor JP, Patankar MS. Peritoneal natural killer cells from epithelial ovarian cancer patients show an altered phenotype and bind to the tumour marker MUC16 (CA125). Immunology. 2007; 122:418-429.

9. Coca S, Perez-Piqueras J, Martinez D, Colmenarejo A, Saez MA, Vallejo C, Martos JA, Moreno M. The prognostic significance of intratumoral natural killer cells in patients with colorectal carcinoma. Cancer. 1997; 79:2320-2328.

10. Gooden M, Lampen M, Jordanova ES, Leffers N, Trimbos JB, van der Burg SH, Nijman H, van Hall T. HLA-E expression by gynecological cancers restrains tumor-infiltrating CD8(+) T lymphocytes. Proc Natl Acad Sci U S A. 2011; 108:10656-10661.

11. Webb JR, Milne K, Watson P, Deleeuw RJ, Nelson BH. Tumor-infiltrating lymphocytes expressing the tissue resident memory marker CD103 are associated with increased survival in high-grade serous ovarian cancer. Clin Cancer Res. 2014; 20:434-444.

12. Dong HP, Elstrand MB, Holth A, Silins I, Berner A, Trope CG, Davidson B, Risberg B. NK- and B-cell infiltration correlates with worse outcome in metastatic ovarian carcinoma. Am J Clin Pathol. 2006; 125:451-458.

13. Ishigami S, Natsugoe S, Tokuda K, Nakajo A, Che X, Iwashige H, Aridome K, Hokita S, Aikou T. Prognostic value of intratumoral natural killer cells in gastric carcinoma. Cancer. 2000; 88:577-583.

14. Tian W, Wang L, Yuan L, Duan W, Zhao W, Wang S, Zhang Q. A prognostic risk model for patients with triple negative breast cancer based on stromal natural killer cells, tumor-associated macrophages and growth-arrest specific protein 6. Cancer Sci. 2016; 107:882-889.

15. Turkseven MR, Oygur T. Evaluation of natural killer cell defense in oral squamous cell carcinoma. Oral Oncol. 2010; 46:e34-37.

16. Sconocchia G, Eppenberger S, Spagnoli GC, Tornillo L, Droeser R, Caratelli S, Ferrelli F, Coppola A, Arriga R, Lauro D, Iezzi G, Terracciano L, Ferrone S. NK cells and $\mathrm{T}$ cells cooperate during the clinical course of colorectal cancer. Oncoimmunology. 2014; 3:e952197.

17. Vivier E, Tomasello E, Baratin M, Walzer T, Ugolini S. Functions of natural killer cells. Nat Immunol. 2008; 9:503-510.

18. Andre P, Castriconi R, Espeli M, Anfossi N, Juarez T, Hue S, Conway H, Romagne F, Dondero A, Nanni M, Caillat-Zucman S, Raulet DH, Bottino C, et al. Comparative analysis of human NK cell activation induced by NKG2D and natural cytotoxicity receptors. Eur J Immunol. 2004; 34:961-971.

19. Imai K, Matsuyama S, Miyake S, Suga K, Nakachi K. Natural cytotoxic activity of peripheral-blood lymphocytes and cancer incidence: an 11-year follow-up study of a general population. Lancet. 2000; 356:1795-1799.

20. Morvan MG, Lanier LL. NK cells and cancer: you can teach innate cells new tricks. Nat Rev Cancer. 2016; 16:7-19.

21. Pesce S, Tabellini G, Cantoni C, Patrizi O, Coltrini D, Rampinelli F, Matta J, Vivier E, Moretta A, Parolini S, Marcenaro E. B7-H6-mediated downregulation of NKp30 in NK cells contributes to ovarian carcinoma immune escape. Oncoimmunology. 2015; 4:e1001224.

22. Berek JS, Bast RC Jr, Lichtenstein A, Hacker NF, Spina CA, Lagasse LD, Knapp RC, Zighelboim J. Lymphocyte cytotoxicity in the peritoneal cavity and blood of patients with ovarian cancer. Obstet Gynecol. 1984; 64:708-714.

23. Tran E, Nielsen JS, Wick DA, Ng AV, Johnson LD, Nesslinger NJ, McMurtrie E, Webb JR, Nelson BH. Polyfunctional T-cell responses are disrupted by the ovarian cancer ascites environment and only partially restored by clinically relevant cytokines. PLoS One. 2010; 5:e15625.

24. da Silva RF, Yoshida A, Cardozo DM, Jales RM, Paust S, Derchain S, Guimaraes F. Natural Killer Cells Response to IL-2 Stimulation Is Distinct between Ascites with the Presence or Absence of Malignant Cells in Ovarian Cancer Patients. Int J Mol Sci. 2017; 18:856.

25. Felices M, Chu S, Kodal B, Bendzick L, Ryan C, Lenvik AJ, Boylan KLM, Wong HC, Skubitz APN, Miller JS, Geller MA. IL-15 super-agonist (ALT-803) enhances natural killer (NK) cell function against ovarian cancer. Gynecol Oncol. 2017; 145:453-461.

26. Kloss S, Chambron N, Gardlowski T, Weil S, Koch J, Esser R, Pogge von Strandmann E, Morgan MA, Arseniev L, Seitz O, Kohl U. Cetuximab Reconstitutes ProInflammatory Cytokine Secretions and Tumor-Infiltrating 
Capabilities of sMICA-Inhibited NK Cells in HNSCC Tumor Spheroids. Front Immunol. 2015; 6:543.

27. Cany J, van der Waart AB, Spanholtz J, Tordoir M, Jansen JH, van der Voort R, Schaap NM, Dolstra H. Combined IL-15 and IL-12 drives the generation of CD34-derived natural killer cells with superior maturation and alloreactivity potential following adoptive transfer. Oncoimmunology. 2015; 4:e1017701.

28. Cany J, van der Waart AB, Tordoir M, Franssen GM, Hangalapura BN, de Vries J, Boerman O, Schaap N, van der Voort R, Spanholtz J, Dolstra H. Natural killer cells generated from cord blood hematopoietic progenitor cells efficiently target bone marrow-residing human leukemia cells in NOD/ SCID/IL2Rg(null) mice. PLoS One. 2013; 8:e64384.

29. Roeven MW, Thordardottir S, Kohela A, Maas F, Preijers F, Jansen JH, Blijlevens NM, Cany J, Schaap N, Dolstra H. The Aryl Hydrocarbon Receptor Antagonist StemRegenin1 Improves In Vitro Generation of Highly Functional Natural Killer Cells from CD34(+) Hematopoietic Stem and Progenitor Cells. Stem Cells Dev. 2015; 24:2886-2898.

30. Spanholtz J, Tordoir M, Eissens D, Preijers F, van der Meer A, Joosten I, Schaap N, de Witte TM, Dolstra H. High log-scale expansion of functional human natural killer cells from umbilical cord blood CD34-positive cells for adoptive cancer immunotherapy. PLoS One. 2010; 5:e9221.

31. Geller MA, Knorr DA, Hermanson DA, Pribyl L, Bendzick L, McCullar V, Miller JS, Kaufman DS. Intraperitoneal delivery of human natural killer cells for treatment of ovarian cancer in a mouse xenograft model. Cytotherapy. 2013; 15:1297-1306.

32. Geller MA, Miller JS. Use of allogeneic NK cells for cancer immunotherapy. Immunotherapy. 2011; 3:1445-1459.

33. Hermanson DL, Bendzick L, Pribyl L, McCullar V, Vogel RI, Miller JS, Geller MA, Kaufman DS. Induced Pluripotent Stem Cell-Derived Natural Killer Cells for Treatment of Ovarian Cancer. Stem Cells. 2016; 34:93-101.

34. Bachanova V, Cooley S, Defor TE, Verneris MR, Zhang B, McKenna DH, Curtsinger J, Panoskaltsis-Mortari A, Lewis D, Hippen K, McGlave P, Weisdorf DJ, Blazar BR, et al. Clearance of acute myeloid leukemia by haploidentical natural killer cells is improved using IL-2 diphtheria toxin fusion protein. Blood. 2014; 123:3855-3863.

35. Giannattasio A, Weil S, Kloess S, Ansari N, Stelzer EH, Cerwenka A, Steinle A, Koehl U, Koch J. Cytotoxicity and infiltration of human NK cells in In Vivo-like tumor spheroids. BMC Cancer. 2015; 15:351.

36. Bhat R, Watzl C. Serial killing of tumor cells by human natural killer cells - enhancement by therapeutic antibodies. PLoS One. 2007; 2:e326.

37. Ames E, Canter RJ, Grossenbacher SK, Mac S, Chen M, Smith RC, Hagino T, Perez-Cunningham J, Sckisel GD, Urayama S, Monjazeb AM, Fragoso RC, Sayers TJ, et al. NK Cells Preferentially Target Tumor Cells with a Cancer Stem Cell Phenotype. J Immunol. 2015; 195:4010-4019.
38. Kozlowska AK, Kaur K, Topchyan P, Jewett A. Novel strategies to target cancer stem cells by NK cells; studies in humanized mice. Front Biosci (Landmark Ed). 2017; 22:370-384.

39. Koh J, Lee SB, Park H, Lee HJ, Cho NH, Kim J. Susceptibility of CD24(+) ovarian cancer cells to anticancer drugs and natural killer cells. Biochem Biophys Res Commun. 2012; 427:373-378.

40. Choi PJ, Mitchison TJ. Imaging burst kinetics and spatial coordination during serial killing by single natural killer cells. Proc Natl Acad Sci USA. 2013; 110:6488-6493.

41. Rosario M, Liu B, Kong L, Collins LI, Schneider SE, Chen X, Han K, Jeng EK, Rhode PR, Leong JW, Schappe T, Jewell BA, Keppel CR, et al. The IL-15-Based ALT-803 Complex Enhances FcgammaRIIIa-Triggered NK Cell Responses and In Vivo Clearance of B Cell Lymphomas. Clin Cancer Res. 2016; 22:596-608.

42. Vivier E, Nunes JA, Vely F. Natural killer cell signaling pathways. Science. 2004; 306:1517-1519.

43. Vivier E, Raulet DH, Moretta A, Caligiuri MA, Zitvogel L, Lanier LL, Yokoyama WM, Ugolini S. Innate or adaptive immunity. The example of natural killer cells. Science. 2011; 331:44-49.

44. Timmermans M, Sonke GS, Van de Vijver KK, van der Aa MA, Kruitwagen R. No improvement in long-term survival for epithelial ovarian cancer patients: A populationbased study between 1989 and 2014 in the Netherlands. Eur J Cancer. 2017; 88:31-37.

45. Almeida-Oliveira A, Smith-Carvalho M, Porto LC, CardosoOliveira J, Ribeiro Ados S, Falcao RR, Abdelhay E, Bouzas LF, Thuler LC, Ornellas MH, Diamond HR. Age-related changes in natural killer cell receptors from childhood through old age. Hum Immunol. 2011; 72:319-329.

46. Kang YJ, Jeung IC, Park A, Park YJ, Jung H, Kim TD, Lee HG, Choi I, Yoon SR. An increased level of IL-6 suppresses NK cell activity in peritoneal fluid of patients with endometriosis via regulation of SHP-2 expression. Hum Reprod. 2014; 29:2176-2189.

47. Lieber S, Reinartz S, Raifer H, Finkernagel F, Dreyer T, Bronger H, Jansen JM, Wagner U, Worzfeld T, Muller R, Huber M. Prognosis of ovarian cancer is associated with effector memory CD8(+) T cell accumulation in ascites, CXCL9 levels and activation-triggered signal transduction in T cells. Oncoimmunology. 2018; 7:e1424672.

48. Worzfeld T, Pogge von Strandmann E, Huber M, Adhikary T, Wagner U, Reinartz S, Muller R. The Unique Molecular and Cellular Microenvironment of Ovarian Cancer. Front Oncol. 2017; 7:24.

49. Nham T, Poznanski SM, Fan IY, Shenouda MM, Chew MV, Lee AJ, Vahedi F, Karimi Y, Butcher M, Lee DA, Hirte H, Ashkar AA. Ex vivo-expanded NK cells from blood and ascites of ovarian cancer patients are cytotoxic against autologous primary ovarian cancer cells. Cancer Immunol Immunother. 2018; 67:575-587. 
50. Chretien AS, Fauriat C, Orlanducci F, Rey J, Borg GB, Gautherot E, Granjeaud S, Demerle C, Hamel JF, Cerwenka A, von Strandmann EP, Ifrah N, Lacombe C, et al. NKp30 expression is a prognostic immune biomarker for stratification of patients with intermediate-risk acute myeloid leukemia. Oncotarget. 2017; 8:49548-63. https:// doi.org/10.18632/oncotarget.17747.

51. Lai P, Rabinowich H, Crowley-Nowick PA, Bell MC, Mantovani G, Whiteside TL. Alterations in expression and function of signal-transducing proteins in tumor-associated $\mathrm{T}$ and natural killer cells in patients with ovarian carcinoma. Clin Cancer Res. 1996; 2:161-173.

52. Ioannides CG, Platsoucas CD, Rashed S, Wharton JT, Edwards CL, Freedman RS. Tumor cytolysis by lymphocytes infiltrating ovarian malignant ascites. Cancer Res. 1991; 51:4257-4265.

53. Rhode PR, Egan JO, Xu W, Hong H, Webb GM, Chen X, Liu B, Zhu X, Wen J, You L, Kong L, Edwards AC, Han K, et al. Comparison of the Superagonist Complex, ALT-803, to IL15 as Cancer Immunotherapeutics in Animal Models. Cancer Immunol Res. 2016; 4:49-60.

54. Han KP, Zhu X, Liu B, Jeng E, Kong L, Yovandich JL, Vyas VV, Marcus WD, Chavaillaz PA, Romero CA, Rhode PR, Wong HC. IL-15:IL-15 receptor alpha superagonist complex: high-level co-expression in recombinant mammalian cells, purification and characterization. Cytokine. 2011; 56:804-810. 